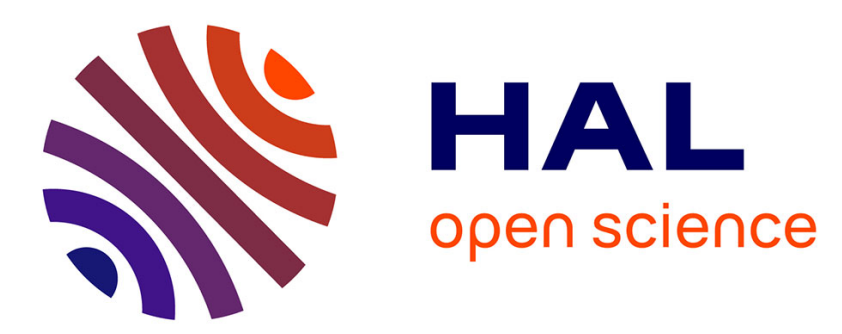

\title{
Study of a Topology of Low-Loss Magnetic Component for PCB-Embedding
}

Yoann Pascal, Mickael Petit, Denis Labrousse, François Costa

\section{To cite this version:}

Yoann Pascal, Mickael Petit, Denis Labrousse, François Costa. Study of a Topology of Low-Loss Magnetic Component for PCB-Embedding. 2018 7th Electronic System-Integration Technology Conference (ESTC), Sep 2018, Dresden, Germany. hal-01880799

\section{HAL Id: hal-01880799 \\ https://hal.science/hal-01880799}

Submitted on 25 Sep 2018

HAL is a multi-disciplinary open access archive for the deposit and dissemination of scientific research documents, whether they are published or not. The documents may come from teaching and research institutions in France or abroad, or from public or private research centers.
L'archive ouverte pluridisciplinaire HAL, est destinée au dépôt et à la diffusion de documents scientifiques de niveau recherche, publiés ou non, émanant des établissements d'enseignement et de recherche français ou étrangers, des laboratoires publics ou privés. 


\section{Study of a Topology of Low-Loss Magnetic Component for PCB-Embedding}

\author{
Yoann Pascal, Mickaël Petit, Denis Labrousse \\ Lab. SATIE \\ CNAM \\ Paris, France \\ \{yoann.pascal, mickael.petit, denis.labrousse\}@ satie.ens-cachan.fr
}

\begin{abstract}
PCBembedded inductor- and transformer- windings is presented in details. Two prototypes are manufactured, one using a conventional technique and the other using our process. The prototypes have similar DC-resistances and inductances but the AC-resistance of the conventional one is up to 3.6 times higher than the other. Using the proposed design in a $28 \mathrm{~V}$ to $12 \mathrm{~V}-5 \mathrm{~A}$ buck chopper yields a 5-points increase of the efficiency. In the end, the proposed process is cost-effective and can be implemented on standard PCB manufacturing assembly-lines. It is barely more complicated than the common method, using PCBtracks as windings, but results in much smaller losses.
\end{abstract}

Keywords—integrated inductor, packaging, passive component, PCB-embedding, power electronics, Printed Circuit Board,

\section{INTRODUCTION}

Passive components manufactured using standard Printed Circuit Board (PCB) manufacturing techniques might pave the way toward economical, highly repeatable and low profile magnetic components. Planar transformers, composed of PCBwindings and clip-on low-profile ferrite cores, have been used for a few decades. Many research papers have dealt with integrated and planar magnetic components, including coils, transformers and resonant circuits. These publications focused on manufacturing techniques $[1,2,3,4]$, modelling $[1,5]$, optimization [3], and simulation [1, 6, 7, 8].

Various structures have been studied, planar [2, 9], with solenoid-like structures (windings surrounding the magnetic core - like a toroid inductor) $[1,4,10]$, with pot-core-like structures (core surrounding the windings - like with a PQcore) [3] or air-core components [6, 7, 8].

One of the simplest structures consists in one or several copper spirals, made of a PCB-printed copper track, placed between two plates of magnetic material [11, 12, 13, 14] (Fig. 1, top). This component, hereafter called "Planar-copper coil" (or "P-coil"), can be used as either an inductor or a highleakage (due to the long air-gap between the magnetic plates) transformer. It is highly economical and easy to manufacture using standard PCB manufacturing processes. The copper tracks are parallel to the magnetic plates and, a priori, much wider than thick $(v \gg t)$. Then, the orthogonality of the copper tracks and the magnetic field in the air-gap results in high eddy-currents, and thus high AC-copper loss.

This paper presents a structure of coil (Fig. 1, bottom) for

This work was supported by a grant overseen by the French National Research Agency (ANR-15-CE05-0010).

\author{
François Costa \\ Lab. SATIE \\ UPEC, ESPE \\ St Denis, France \\ francois.costa@satie.ens-cachan.fr
}

which these losses are greatly reduced: in these "Verticalcopper coils" (or "V-coils" for short), the copper tracks are parallel to the magnetic field. The manufacturing process is simple, inexpensive and compatible with conventional PCBmanufacturing facilities.

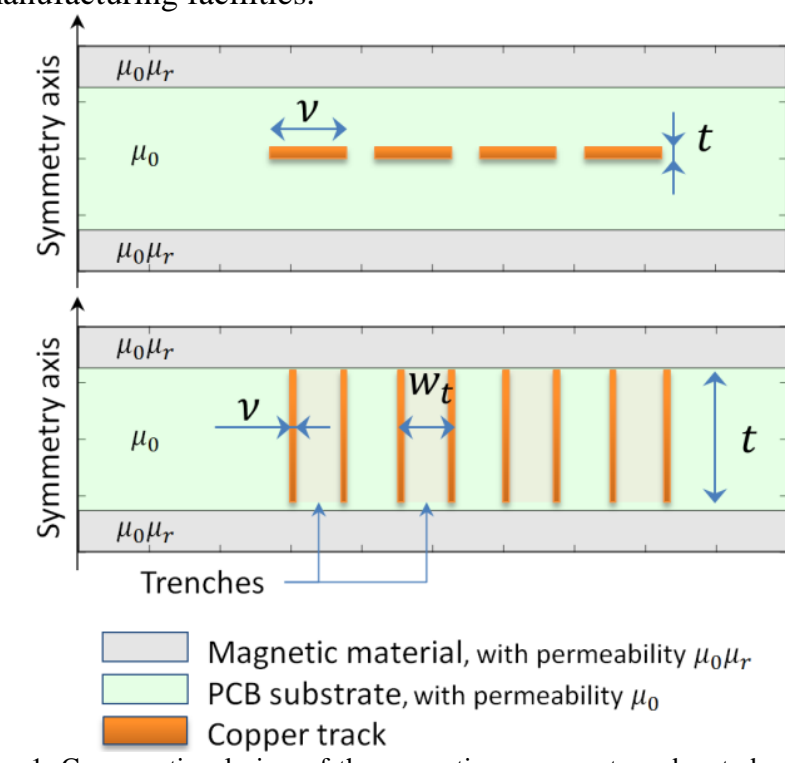

Fig. 1. Cross-sectional view of the magnetic components under study. P-coil (top) and V-coil (bottom)

The developed manufacturing process is described in section II. Two coils were then manufactured and compared: one was built using the conventional method whereas the other was manufactured using our process; a comparison is made between them in section III. The results and their scope are discussed in section IV. Section V concludes the paper.

\section{MANUFACTURING PROCESS OF A V-COIL}

The manufacturing process for a V-coil (Fig. 1, bottom) is the following (Fig. 2) :

a. A standard PCB substrate is considered;

b. One or several spiral-shaped trenches of width $w_{t}$ are machined in the substrate using a milling machine;

c. A seed layer is deposited on the surface of the PCB;

d. A layer of copper of thickness $v$ is electro-deposited on the seed layer;

e. The copper located on the plane surfaces of the PCB (for $|2 z|>t$, cf. Fig. 2) is mechanically removed using a milling machine; 


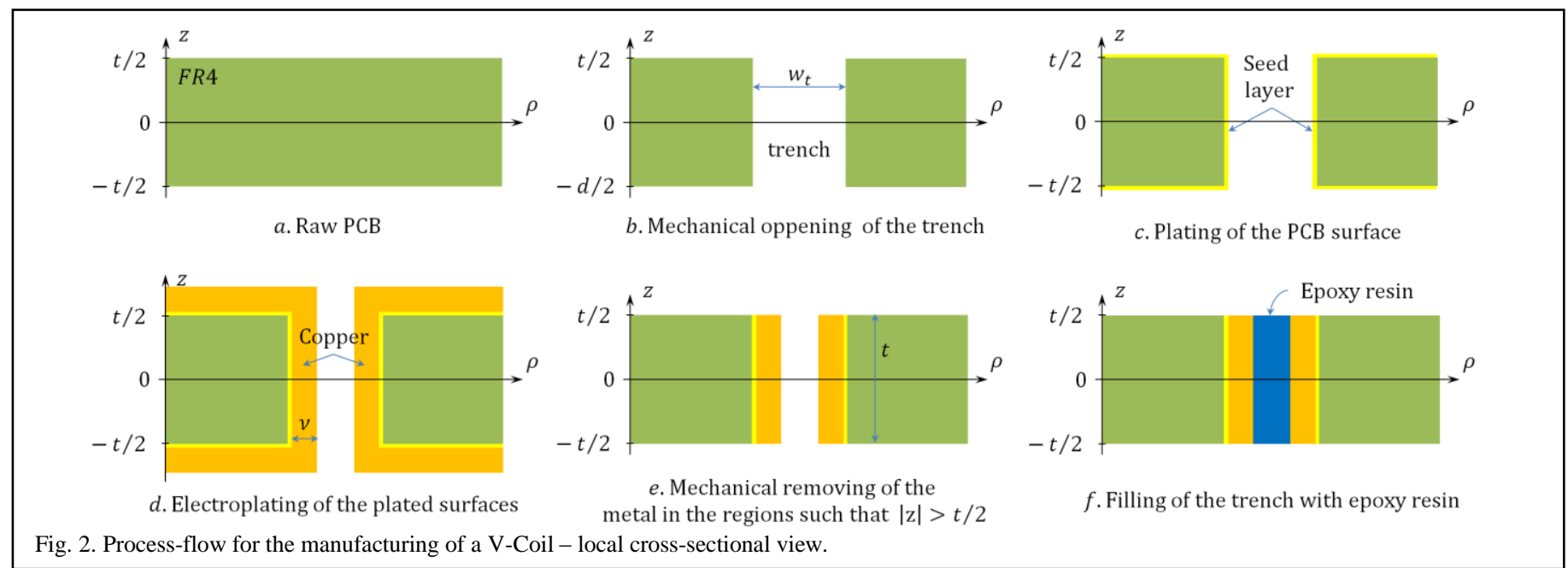

f. The trench is filled with epoxy resin.

At the end of the process, two spirals of copper are moulded into the substrate and located on what used to be the edges of the trench. Each of these spirals can be used as a winding, or be connected to one another to form a simple inductor. Steps $f$ may also be performed before step $e$.

Similar structures have already been studied for on-chip integration [15].

One circular plates of magnetic material can then be placed on each side of the device, so as to increase the overall inductance whilst improving the ElectroMagnetic Compliance (EMC) of the device. PCBs can then be laminated on both sides of the device in order to allow the manufacturing of an electrical circuit or to serve as thermal drains.

\section{COMPARISON: V-COILS VS. P-COIL}

Two inductors, one $\mathrm{V}$-coil and one $\mathrm{P}$-coil, with very similar dimensions, are considered in this section. The P-coil was an inductor (with a single winding) whereas the V-coil had two windings: one on each edge of the machined trench. For the comparison to be as fair as possible, only one of these windings was used while the other was left floating.

Both coils were manufactured and their performances are compared in the following.

TABLE I

SIZING OF THE PROTOTYPED INDUCTORS

\begin{tabular}{|c|c|c|c|c|}
\hline Symbol & Parameter & $\begin{array}{c}\mathrm{P}- \\
\text { coil }\end{array}$ & $\begin{array}{c}\mathrm{V}- \\
\text { coil }\end{array}$ & Unit \\
\hline$t$ & Thickness of the copper tracks & 0.07 & 1.27 & $\mathrm{~mm}$ \\
\hline$v$ & Width of the copper tracks & 1.9 & 0.09 & $\mathrm{~mm}$ \\
\hline$d$ & Distance between the MPs & 1.5 & 1.5 & $\mathrm{~mm}$ \\
\hline- & Overall inductor thickness & 2.4 & 2.4 & $\mu \mathrm{m}$ \\
\hline$\rho_{e}$ & Radius of the MPs & 20.5 & 20.5 & $\mathrm{~mm}$ \\
\hline$\mu_{r}$ & Relative permeability of the MPs & 130 & 130 & - \\
\hline$N_{w}$ & Number of windings & 1 & 2 & - \\
\hline$N_{t}$ & Number of turns per winding & 4 & 4 & - \\
\hline$\chi$ & Spiral step & 3 & 3 & $\mathrm{~mm}$ \\
\hline$w_{t}$ & Width of the trench & N.A. & 1.5 & $\mathrm{~mm}$ \\
\hline$\rho_{0}$ & Internal turn mean radius & 6.6 & 6.6 & $\mathrm{~mm}$ \\
\hline
\end{tabular}

\section{A. Prototypes under study}

The dimensions of the coils under study are given in Table I. A photography of the V-coil and the layout of the P-coil are given in Fig. 3.

The thickness of copper deposited for the V-coil was adjusted so that both inductors would have the same DCresistance.

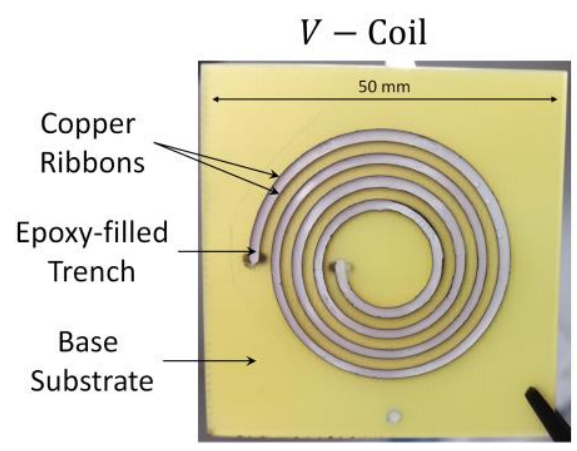

$P$ - Coil: layout

Fig. 3. Photography of the V-coil without magnetic plates (left) and layout of the P-coil under study (right).

As for the magnetic material, $180 \mu \mathrm{m}$-thick sheets of sintered ferrite with reference IBF15, from TDK, were used [16]. This material is primarily designed to serve as ElectroMagnetic Interference (EMI) shield or absorber; its relative permeability is $\mu_{r}=130$ up to about $13 \mathrm{MHz}$, frequency at which core losses start to increase greatly. The relative permeability (Fig. 4) was measured using a coaxial cell and an E4990a impedance analyser; it was assumed that the uncertainty on the geometrical dimensions was $\pm 500 \mu \mathrm{m}$. The saturation induction, measured in [4], is about $350 \mathrm{mT}$. The specified surface resistivity is $>1 \mathrm{G} \Omega / \square$. Two sheets were stacked so as to get $360 \mu \mathrm{m}$-thick magnetic plates. Similar materials were used in $[4,13,14,17]$.

In conventional PCB-manufacturing facilities, the seed layer (cf. Fig. 2.c) could be made using electroless copper or palladium, or even low-cost carbon metallization. However, the $\mathrm{V}$-coil considered in the following was manufactured using the apparatus available in the lab: a $100 \mathrm{~nm}$-thick layer of gold was used. 
Copper was deposited in two steps. First, a rather low, static, current density $\left(2 \mathrm{~mA} / \mathrm{cm}^{2}\right.$, for $\left.1 \mathrm{~h}\right)$ was used so as to produce a smooth and regular deposit whilst preventing any risk of seed-layer delamination. Then, the layer was thickened using a higher, static, current density $\left(20 \mathrm{~mA} / \mathrm{cm}^{2}\right.$, for $\left.5.5 \mathrm{~h}\right)$.

The P-coil was manufactured using a standard PCB with $70 \mu \mathrm{m}$-thick copper laminate.

The magnetic plates of the two prototypes considered in the following sections were glued on the substrate with embedded windings; no further moulding was performed.

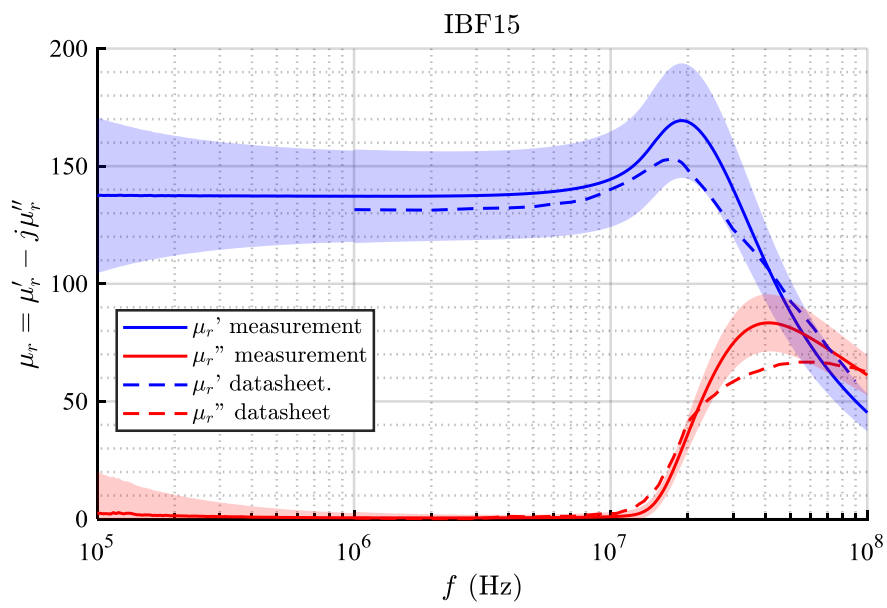

Fig. 4. Measured relative permeability of IBF15 (plain lines; shaded area: estimated uncertainty) and data taken from the datasheet (dashed lines).

\section{B. FEM Simulation}

The two coils under study were simulated using the FEMM software [18], which performs Finite Element Analyses. Axisymmetry was assumed; 2D-simulations were therefore performed. The meshing was smaller than one fifth of the smallest dimension of the meshed zone or than one fifth of the skindepth - whichever was smallest. As for the boundary conditions, the impedance of an unbounded domain was emulated using seven circular concentric shells with various magnetic properties. These boundary conditions were automatically created using the @mi_makeABC function and its default settings, implemented in the software [19]. The frequency dependence of the complex-valued permeability of the magnetic material (including small signal losses, as defined in the material datasheet [16]) was taken into account by the software. The PCB substrate and the surrounding air were assimilated to vacuum.

The simulated small signal magnetic flux densities in the devices are given in Fig. 5. This shows that the magnetic flux in the air-gap is primarily axial whereas it is radial in the magnetic plates. In the P-coil (Fig. 5. top), the field is therefore orthogonal to the copper track, resulting in high Eddy current and therefore high copper losses. In the V-coil, on the other hand, the copper foils and the field are parallel, resulting in reduced eddy currents. Furthermore, the flux density above and below the device is low; an electronic circuit or heatsinks could therefore be placed on the top and bottom sides of the device without inducing malfunctions or additional loss.

The simulated inductance and resistance vs. frequency are given in Fig. 6.

The simulated current densities in the V-coil (Fig. 7, bottom) is much smaller and more homogenous than in the $\mathrm{P}$ coil (Fig. 7, top), which explains the resistance gap visible in Fig. 6.

\section{Measured Impedance}

The impedance of the Devices Under Test (DUT) were measured using an E4990a impedance analyser (SOL calibration, measurement time " 3 ", excitation voltage: $500 \mathrm{mV}$ ). The FEMM-simulated and measured impedances are given in Fig. 6.

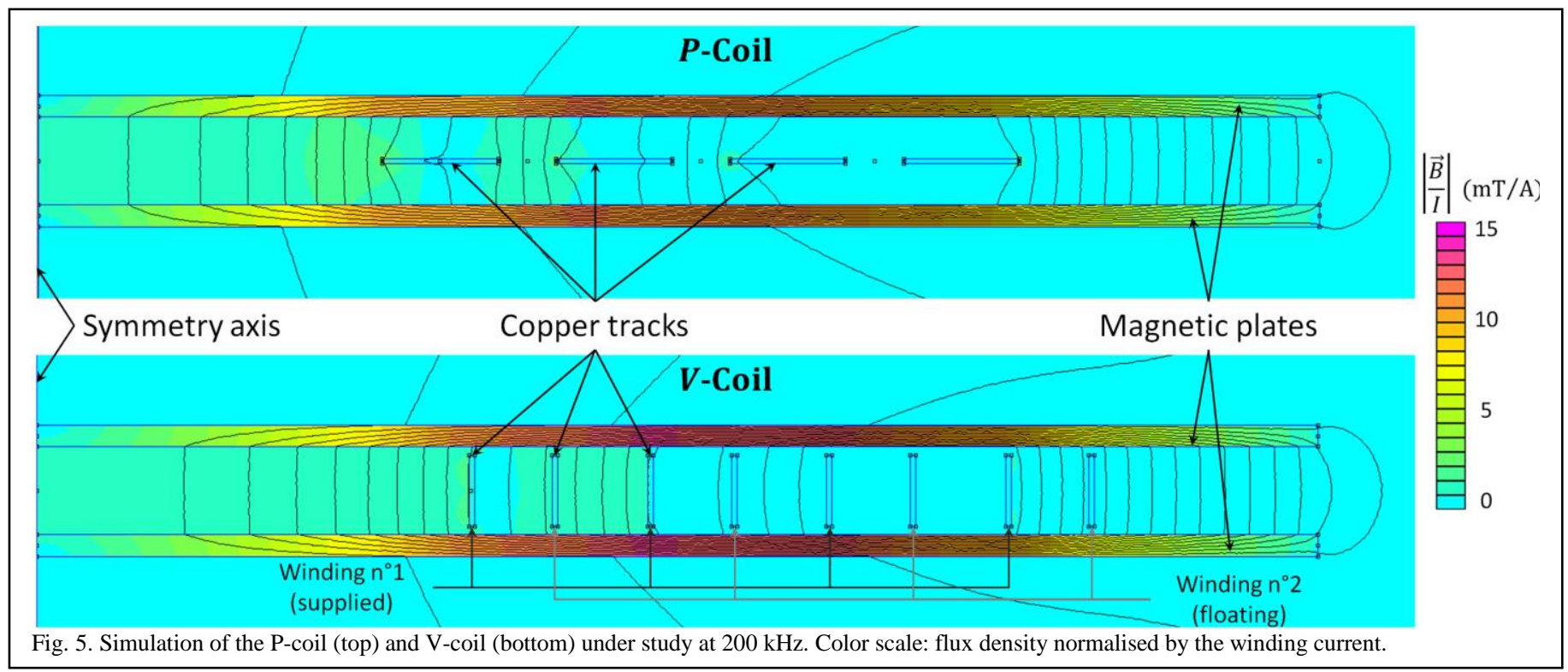




\section{$\left(R_{s}, L_{s}\right)$-model of the $\mathrm{P}$ - and $\mathrm{V}$ - coils}
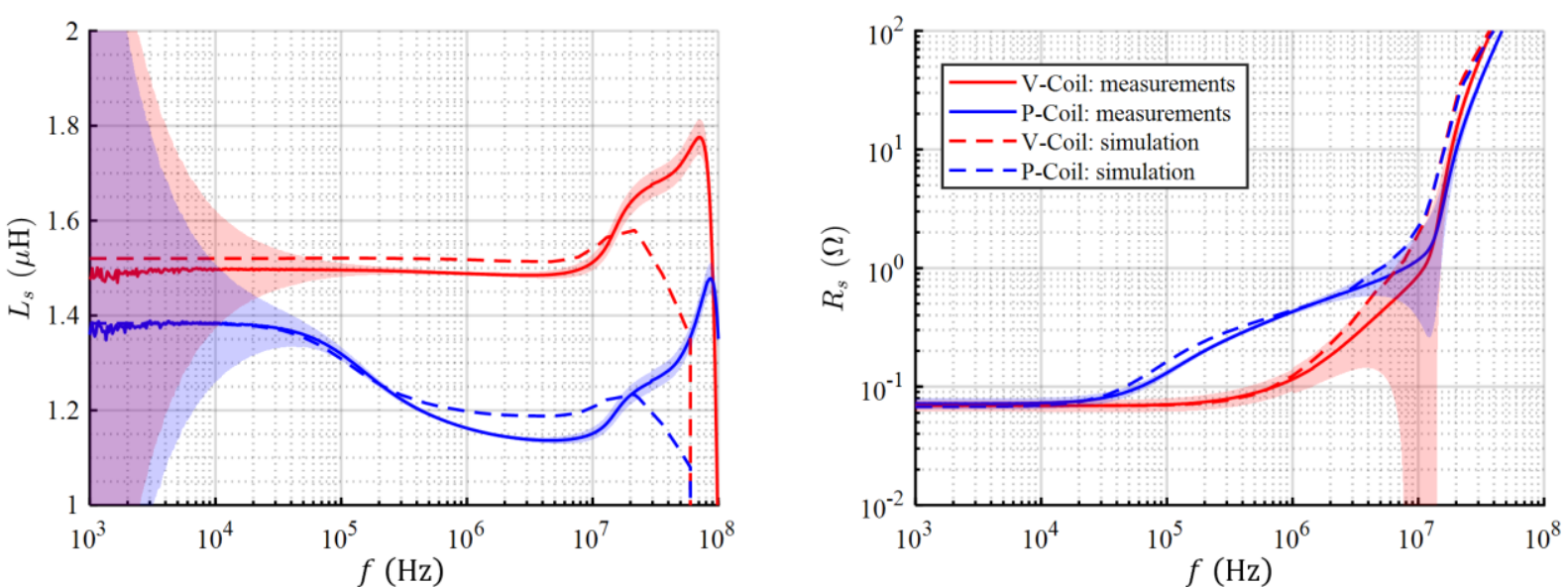

Fig. 6. Inductance (left) and resistance (right) of the DUTs. Shaded areas: uncertainty on the measurements.

By design, both coils have same DCR: $80 \mathrm{~m} \Omega$. The lowfrequency inductance of the P-coil is $7 \%$ smaller than that of the $\mathrm{V}$-coil, in particular because of the difference in current distributions inside the copper tracks.

From $10 \mathrm{MHz}$, the inductance increases due to the peak in permeability (see Fig. 4) while the resistance increase very fast because of the increase in $\mu_{r}^{\prime \prime}$, which characterises small signal core losses. The drop in inductance observed on the P-coil around $100 \mathrm{kHz}$ can be explained by the field reconfiguration between the magnetic plates: from this frequency, Eddy currents induced in the copper plates cancel the field above and below them while inducing losses - materialised by an increase in resistance as soon as a few tens of $\mathrm{kHz}$. On the other hand, the inductance of the $\mathrm{V}$-coil remains constant up to $10 \mathrm{MHz}$ and the AC-loss are negligible up to a few hundreds of $\mathrm{kHz}$.

\section{Use in a DC-DC converter}

So as to compare the performances of the two inductors in real-life conditions, they were inserted in a buck chopper. The converter was run in the same conditions with either inductor and the efficiencies were measured and compared.

\section{a) Converter specifications}

The converter was designed to be part of an aircraft power network; the input voltage was $V_{i}=28 \mathrm{~V}$ and various normalised output voltages, ranging from $V_{o}=1.2 \mathrm{~V}$ to
$V_{o}=12 \mathrm{~V}$ were considered. The duty-cycle was adjusted to regulate the output voltage while the switching frequency was varied to keep the converter in Boundary Conduction Mode. Then, assuming a close-to-unity efficiency, the inductor current ripple $\Delta I_{L}$ was linked to the design parameters through the relation:

$$
\Delta I_{L}=2 I_{o}=\frac{\alpha}{L f_{s w}}\left(V_{i}-V_{o}\right) \Leftrightarrow f_{s w}=\frac{\alpha V_{i}}{2 L I_{o}}(\alpha-1)
$$

Where $I_{o}$ is the output current, $L$ the inductance value, $\alpha$ the duty cycle and $f_{s w}$ the switching frequency. The converter maximum output current was limited by the inductor saturation current and temperature increase whereas its minimum value was limited by the maximum switching frequency achievable. More advanced control strategies (burst-mode, pulse skipping, etc. [20]) could have been used to improve the light-load efficiency of the converter. A $80 \mathrm{~V}-10 \mathrm{~A}-15 \mathrm{~m} \Omega_{t y p}$ integrated circuit including a GaN-HEMT switching cell and its driver was used (LMG5200 from Texas Instrument [21]). 5 ns-long dead-times were hardware-controlled. The converter simplified schematics and main parameters are given in Fig. 8 and Table II.

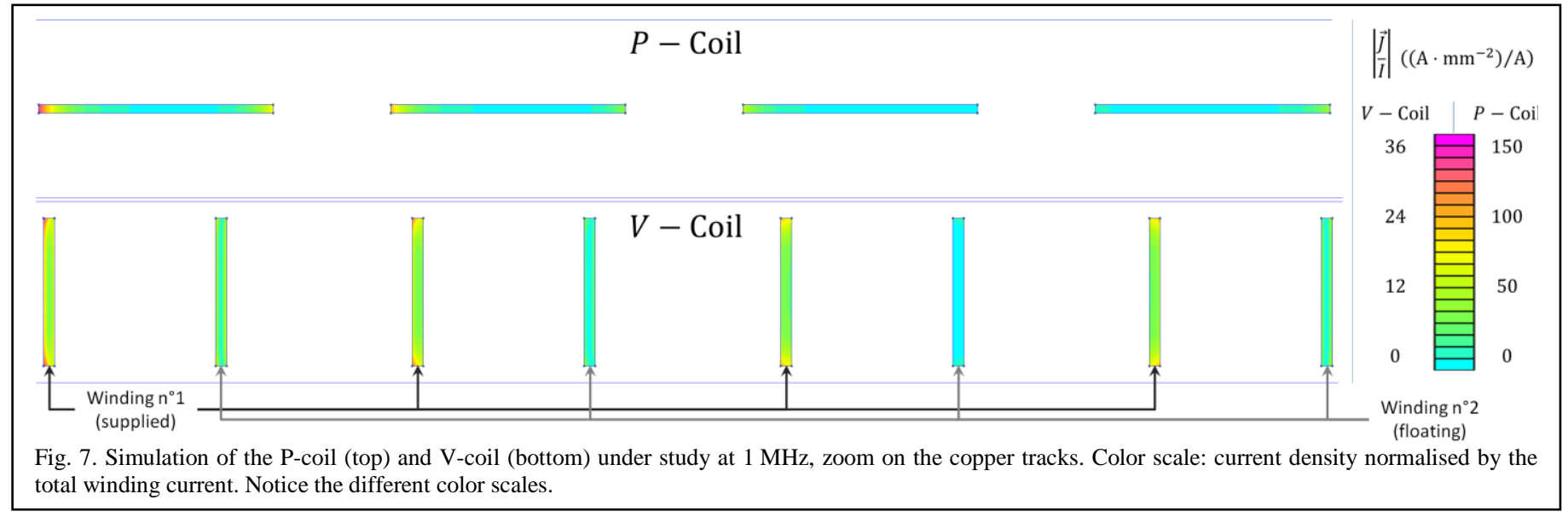




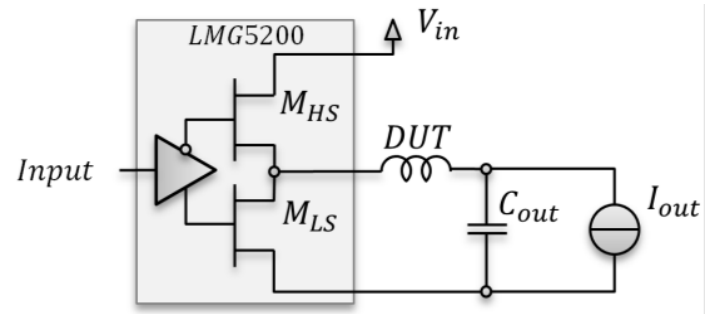

Fig. 8. Converter simplified schematics.

TABLE II

CONVERTER MAIN PARAMETERS

\begin{tabular}{cccc}
\hline \hline Symbol & Parameter & Value & Unit \\
\hline$V_{\text {in }}$ & Input voltage & 28 & $\mathrm{~V}$ \\
$V_{\text {out }}$ & Output voltage & $1.2-12$ & $\mathrm{~V}$ \\
$I_{\text {out }}$ & Output current & $0.2-6$ & $\mathrm{~A}$ \\
$V_{\text {gs }}$ & Transistors control voltage & 5.0 & $\mathrm{~V}$ \\
$C_{\text {in }}$ & Input bypass capacitance, X7R & 5 & $\mu \mathrm{F}$ \\
$C_{\text {out }}$ & Output bypass cap. X5R & 150 & $\mu \mathrm{F}$ \\
- & Integrated half-bridge & LMG5200 & - \\
$f_{\text {sw }}$ & Switching frequency & $<4$ & $\mathrm{MHz}$ \\
\hline \hline
\end{tabular}

\section{b) Measurement}

Four digital multi-meters IDM8351 (5.5 digits, DC voltage basic precision: $120 \mathrm{ppm}$ ) were used to measure the input and output voltages and currents, from which the efficiency was deduced. The measurements were performed at room temperature, after thermal stabilisation of the converter.

The thermal resistance of the P-coil was measured by selfheating the winding and using the temperature dependence of its electrical resistance. A DC current $I$ was forced in the winding, the voltage $V$ across which was measured at steady state. Given the electrical resistance $R_{0}$ of the winding at room temperature and the temperature coefficient of $\operatorname{copper} \theta$, the thermal resistance was:

$$
R_{t h}=\frac{1}{\theta V I}\left(\frac{V}{I R_{0}}-1\right)
$$

Then, we measured $R_{\text {th,Pcoil }}=21 \mathrm{KW}^{-1}$.

Since convection accounted for about $95 \%$ of the overall thermal resistance; it was safe to assume that the two coils would have very similar thermal resistance.

\section{c) Simulation}

The power lost in each converter was estimated using Matlab 2017b. The spectrum of the voltage applied to the inductor was calculated assuming that the input and output voltages of the converter were perfectly filtered. Using the complex impedance vs. frequency (measured at room temperature, Fig. 6) of the inductor and neglecting the effects of saturation, the spectrum of the inductor current could be calculated. It was then used to estimate the power lost in the inductor. The effect of the temperature rise of the conductor on its electrical resistance was taken into account as follow. The overall power lost in the component is the sum of the power lost for each spectral component with frequency $f$ and amplitude $I(f)$ :

$$
P=\sum_{f} R(f, T) \cdot I(f)^{2}
$$

Where $R(f, T)$ is the resistance of the component at frequency $f$ and temperature $T$. The dependence wrt the temperature $T$ can, locally, be expressed as:

$$
R(f, T)=R\left(f, T_{0}\right) \cdot\left(1+\theta \cdot\left(T-T_{0}\right)\right)
$$

Where $\theta$ is the conductor temperature coefficient and $T_{0}$ is a reference temperature. Furthermore, given the thermal resistance $R_{t h}$ between the ambient (at temperature $T_{a}$ ) and the conductor (at temperature $T$ ), we can write:

$$
T-T_{a}=R_{t h} \cdot P \quad \Leftrightarrow T=R_{t h} \cdot P+T_{a}
$$

(3) and (4) yield:

$$
P=\left(1+\theta \cdot\left(T-T_{0}\right)\right) \cdot \sum_{f} R\left(f, T_{0}\right) \cdot I(f)^{2}
$$

And then, using (5):

$$
P=\frac{\left(1+\theta \cdot\left(T_{a}-T_{0}\right)\right) \cdot \sum_{f} R\left(f, T_{0}\right) \cdot I(f)^{2}}{1-\theta R_{t h} \cdot \sum_{f} R\left(f, T_{0}\right) \cdot I(f)^{2}}
$$

This demonstration assumes that the spectrum of the inductor current does not depend upon the temperature of the DUT, which is justified since the magnetic material (and therefore the inductance, which primarily determines the current shape) is quite stable in the temperature range of interest. Furthermore, it assumes that the inductor core loss can be estimated using solely measurements performed under small amplitude, sinusoidal, excitation, which is a rather strong hypothesis.

The spectrum of the inductor current was then used to estimate the conduction loss in the switching cell, the temperature dependence of which was also taken into account using the method detailed above. The power lost in the bypass capacitors were estimated similarly.

Other losses were estimated using well-known formulas, detailed for instance in [22].

\section{d) Results}

The calculated and measured efficiencies are given in Fig. 10. The converter is always more efficient when using the $\mathrm{V}$ coil than the P-coil; the gap is often as high as 5 points.

The shape of the efficiency curves are as expected: the variations of the efficiency vs. the load current results from the opposite variations of the switching and DC-conduction losses. As a matter of fact, the switching frequency, and thus the switching losses, is inversely proportional to the load current (cf. (1)) whereas the DC-conduction losses increase as the square of the load current. The variations of AC-conduction loss are more complex due to the opposite variations of the resistance and AC-current with frequency. The peak efficiency is reached for load currents between 1.5 $\mathrm{A}$ and $2 \mathrm{~A}$.

For a given loading, the switching loss will always be 6 to $25 \%$ smaller with the V-coil due to its higher inductance - and therefore smaller switching frequency. However, for higher $I_{o}$ values, the resistive loss in the coil starts to dominate and the benefit of using a V-coil rather than a P-coil is made clear. 
The peak power density, reached for $I_{o}=6 \mathrm{~A} \& V_{o}=$ $11.8 \mathrm{~V}$, was $15 \mathrm{~kW} / \mathrm{l}$; the efficiency of the converter using a $\mathrm{V}$ coil at this point was $87 \%$.

As an example, the calculated loss distribution of the circuit converting $28 \mathrm{~V}$ into $11.8 \mathrm{~V}$ is given in Fig. 9. The plots show that using the proposed coil manufacturing technique leads to a relative reduction of the copper loss in the entire $I_{o}$ range.
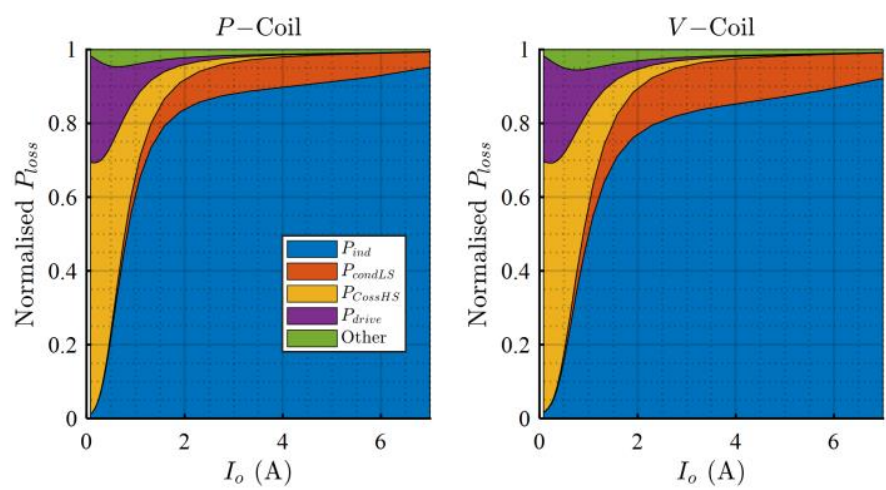

Fig. 9. Estimated normalised loss distribution: with a P-coil (left) and a V-coil (right)

\section{DISCUSSION}

\section{A. Coils Sizing}

The relevance of the sizing of the coils is quite questionable but the point was to compare components with similar outlook; working with an optimum design was therefore not required. As a matter of fact, another basis for comparison could have been to fully optimize two converters, given a set of specifications (input and output voltages, output current) and physical constrains (converter or inductor volume or size, available manufacturing line, etc.).

\section{$B$. On the use of the windings of the $V$-coil}

In order to lead the fairest possible comparison, only one of the windings of the V-Coil was used in this study whilst the other had been left floating. This choice would however make little sense in any other context and the second winding could be taken advantage of. For instance, both windings could be series- or parallel- connected in order to increase the inductance or decrease the resistance of the inductor. The device could also be used as a transformer or as coupled inductors.

\section{Possible domain of use of the process}

This paper describes a new way to manufacture PCBembedded windings. Its use is not a priori limited to the structure of magnetic core considered here and could be associated to various other magnetic cores (e.g. planar cores) with similar benefits. The gain compared to conventional designs is, however, concentrated on the AC-copper loss. Given the slightly higher complexity of the proposed structure, it would be mostly useful in converters with high AC spectral components, i.e. high ripple current.

\section{CONCLUSION}

This paper presented a new process for low-cost PCBembedded inductors. A prototype was manufactured and characterised. The results were compared to those obtained using a conventional PCB-embedding technique. It appeared
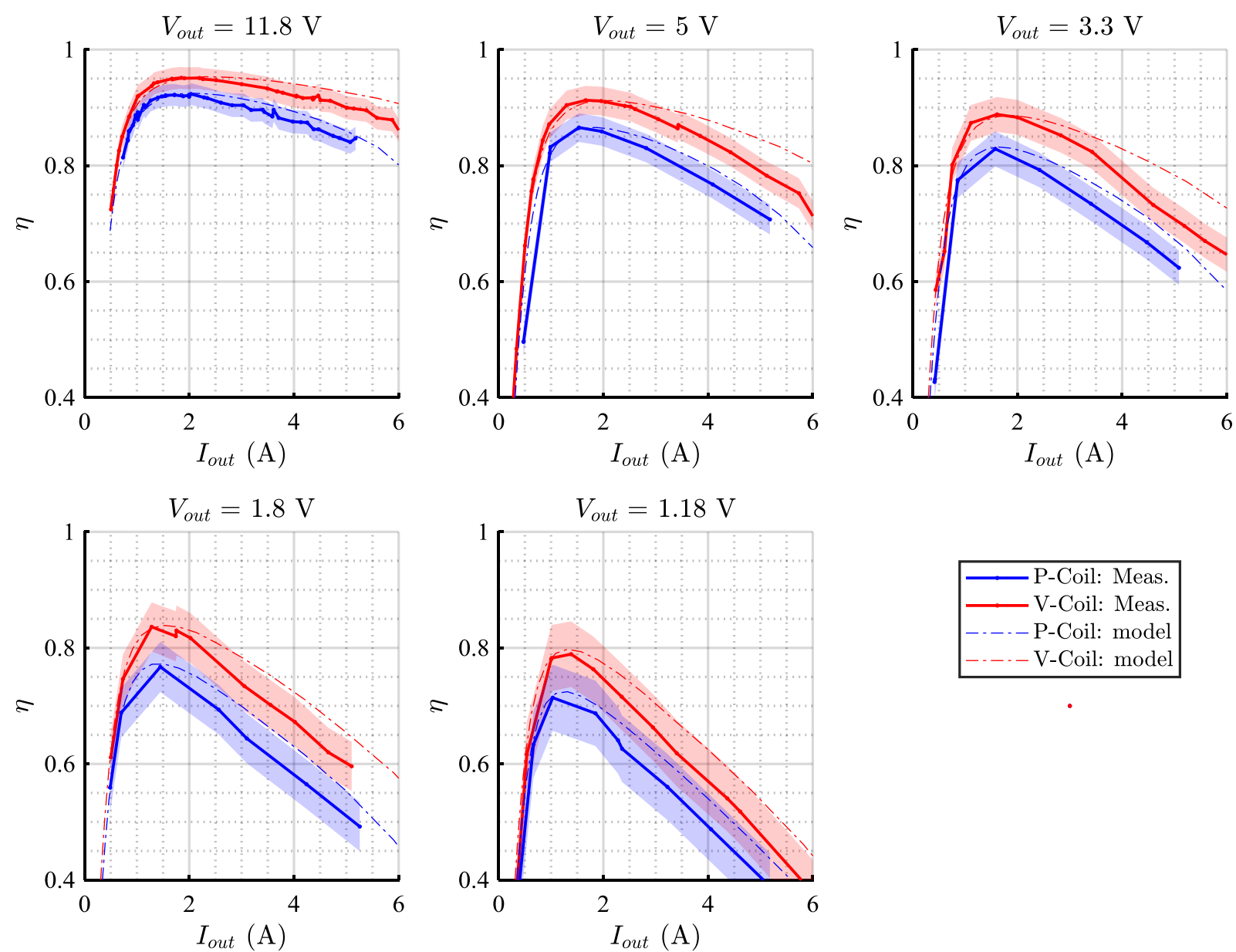

Fig. 10. Efficiency of the buck converters for various output voltages. Red: with a V-coil; Blue: with a P-coil. Shadded area: measurement uncertainty. 
that the proposed process can be used to manufacture inductors and transformers with greatly reduced copper AC-losses thanks to reduced eddy currents.

In the end, the process presented in this paper is costeffective and can be implemented on standard PCB manufacturing assembly-lines. It is barely more complicated than the common method, using PCB-tracks as windings, but results in much smaller losses.

\section{REFERENCES}

[1] J. Qiu, D. V. Harburg and C. R. Sullivan, "A toroidal power inductor using radial-anisotropy thin-film magnetic material based on a hybrid fabrication process," in IEEE Applied Power Electron. Conf. \& Expo. (APEC), Long Beach, CA, USA, 2013.

[2] D. Nicolas, L. Guillaume and M. Stefan, "A 2W, 5MHz, PCB-integration compatible $2.64 \mathrm{~cm} 3$ regulated and isolated power supply for gate driver," in Power Electronics and Applications (EPE'16 ECCE Europe), Karlsruhe, Germany, 2016

[3] J. Serrano, I. Lope, J. Acero, C. Carretero, J. M. Burdío and R. Alonso, "Design and optimization of small inductors on extra-thin PCB for flexible cooking surfaces," IEEE Trans. Indus. Applications, vol. 53, no. 1, pp. 371-379, 2017.

[4] G. Herault, D. Labrousse, A. Mercier and S. Lefebvre, "PCB Integration of a Magnetic Component dedicated to a Power Factor Corrector Converter," in Power Conversion \& Intelligent Motion (PCIM) Europe, Nuremberg, Germany, 2016.

[5] D. V. Harburg, J. Qiu and C. R. Sullivan, "An improved AC loss model for the optimization of planar-coil inductors," in IEEE Control \& Modeling for Power Electron. (COMPEL), Kyoto, Japan, 2012.

[6] I. Lope, C. Carretero, J. Acero, J. M. Burdío and R. Alonso, "Practical issues when calculating AC losses for magnetic devices in PCB implementations," in IEEE Applied Power Electron. Conf. \& Expo. (APEC), Orlando, FL, USA, 2012.

[7] Y. Nour, Z. Ouyang, A. Knott and I. H. H. Jørgensen, "Design and implementation of high frequency buck converter using multi-layer PCB inductor," in IES, IECON, 2016.

[8] M. Biglarbegian, N. Shah, I. Mazhari, J. Enslin and B. Parkhideh, "Design and evaluation of high current PCB embedded inductor for high frequency inverters," in IEEE Applied Power Electron. Conf. \& Expo.(APEC), 2016.

[9] M. A. Bakar, K. Bertilsson and R. Ambatipudi, "High frequency (MHz) soft switched flyback dc-dc converter using GaN switches and sixlayered PCB transformer," in IET Intren. Conf. on Power Electron., Machines and Drives (PEMD), Glasgow, UK, 2016.
[10] R. Perrin, B. Allard, C. Buttay, N. Quentin, W. Zhang, R. Burgos, D. Boroyevic, P. Preciat and D. Martineau, "2 MHz high-density integrated power supply for gate driver in high-temperature applications," in IEEE Applied Power Electron. Conf. \& Expo. (APEC), Long Beach, CA, USA, 2016.

[11] M. Ludwig, M. Duffy, T. O'Donnel, P. McCloskey and S. C. O. Mathuna, "PCB integrated inductors for low power DC/DC converter," IEEE Trans. on Power Electron. Trans., 2003.

[12] E. Waffenschmidt, B. Ackermann and J. A. Ferreira, "Design Method and Material Technologies for Passives in Printed Circuit Board Embedded Circuits," IEEE Trans. Power Electron., vol. 20, no. 3, pp. 576-584, 2005.

[13] S. Tang, S. Hui and H.-H. Chung, "A low-profile power converter using printed-circuit board (PCB) power transformer with ferrite polymer composite," IEEE Trans. Power Electron., vol. 16, no. 4, pp. 493-498, 2001.

[14] C. Marxgut, J. Biela and J. W. Kolar, "Design of a Multi-Cell, DCM PFC Rectifier for a $1 \mathrm{~mm}$ thick, 200W Off-line Power Supply - The Power Sheet," in Inter. Conf. on Integrated Power Electron. Sys., 2010.

[15] M. Brunet, T. O'Donnell, J. O'Brien, P. McCloskey and S. Mathuna, "Thick photoresist development for the fabrication of high aspect ratio magnetic coils," J. of Micromech. and MicrOENG; pp. 444-449, June 2002 .

[16] TDK, "Magnetic Sheets for RFID IFL/IBF series,” June 2016. [Online]. Available: product.tdk.com. [Accessed Janv. 2018]

[17] Y. Su, W. Zhang, Q. Li, F. C. Lee and M. Mu, "High frequency integrated Point of Load (POL) module with PCB embedded inductor substrate," in IEEE Energy Conversion Cong. \& Expo. (ECCE), Denver, CO, USA, 2013.

[18] D. C. Meeker, Finite Element Method Magnetics, V4.2, (25Aug2013 Build), http://www.femm.info.

[19] D. C. Meeker, "Improvised Open Boundary Conditions for Electrostatic Finite Elements," IEEE Trans. on Magnetics, vol. 50, no. 6, 2014.

[20] O. Trescases and Y. Wen, "A survey of light-load efficiency improvement techniques for low-power dc-dc converters," in Power Electron. and ECCE Asia (ICPE \& ECCE), IEEE 8th International Conference on, 2011.

[21] Texas Instrument, "LMG5200 Datasheet, Rev. D," March 2017. [Online]. Available: www.ti.com. [Accessed janv 2018].

[22] Jens Ejury, Infineon Tech. North America (IFNA) Corp, "Buck Converter Design," no. DN 2013-01, 2013. 